\title{
NEUTRON DOSIMETRY IN THE THREE-MILE ISLAND UNIT 2 REACTOR CAVITY WITH SOLID-STATE TRACK RECORDERS
}

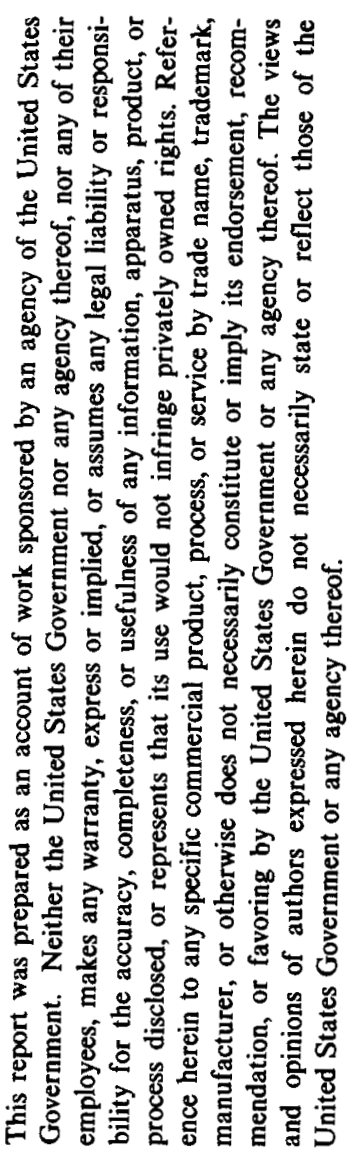

\author{
R. Gold, J.H. Roberts, F.H. Ruddy, \\ C.C. Preston and W.N. McElroy \\ Westinghouse Hanford Company \\ Hanford Engineering Development Laboratory \\ Richland, WA \\ S.V. Rao and J. Greenborg \\ General Public Utilities Nuclear Corporation \\ Middletown, PA
}

HEDL $-S A--3293$

DE85 018470

V.R. Fricke

Burns \& Roe, Inc.

Three-Mile Island Unit 2

Middletown, PA

\author{
13th International Conference on \\ Solid-State Nuclear Track Recorders \\ September 23-27, 1985 \\ Rome, Italy
}

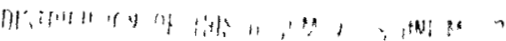

COPYRIGHT LICENSE - By acceptance of this article, the publisher and/or recipient acknowledges the U.S. Government's right to retain a nonexclusive, royalty-free license in and to any copyright covering this paper.

HANFORD ENGINEERING DEVELOPMENT LABORATORY - Operated by Westinghouse Hanford Company, P.O. Box 1970, Richland, WA, a Subsidiary of Westinghouse Electric Corporation. Prepared for the USDOE, Assistant Secretary for Nuclear Energy, Office of Converter Reactor Deployment, under Contract No. DE-AC06-76FF02170, BER No. AG-30-05. 


\section{DISCLAIMER}

This report was prepared as an account of work sponsored by an agency of the United States Government. Neither the United States Government nor any agency Thereof, nor any of their employees, makes any warranty, express or implied, or assumes any legal liability or responsibility for the accuracy, completeness, or usefulness of any information, apparatus, product, or process disclosed, or represents that its use would not infringe privately owned rights. Reference herein to any specific commercial product, process, or service by trade name, trademark, manufacturer, or otherwise does not necessarily constitute or imply its endorsement, recommendation, or favoring by the United States Government or any agency thereof. The views and opinions of authors expressed herein do not necessarily state or reflect those of the United States Government or any agency thereof. 


\section{DISCLAIMER}

Portions of this document may be illegible in electronic image products. Images are produced from the best available original document. 


\title{
NEUTRON DOSIMETRY IN THE THREE-MILE ISLAND UNIT 2 REACTOR CAVITY WITH SOLID-STATE TRACK RECORDERS
}

\author{
Raymond Gold, James H. Roberts, Frank H. Ruddy, \\ Christopher C. Preston and William N. McElroy \\ Westinghouse Hanford Company \\ Hanford Engineering Development Laboratory \\ Richland, washington 99352 \\ Surya V. Rao and Jess Greenborg \\ General Public Utilities Nuclear Corporation \\ Middletown, Pennsylvania 17057 \\ Victor R. Fricke \\ Burns \& Roe, Inc. \\ Three-Mile Island Unit 2 \\ Middletown, Pennsylvania 17057
}

\begin{abstract}
Solid-state track recorder (SSTR) neutron dosimetry has been conducted in the Three-Mile Island Unit 2 (TMI-2) reactor cavity (i.e., the annular gap between the pressure vesse 1 and the biological shield) for nondestructive assessment of the fuel distribution. Two axial stringers were deployed in the annular gap with 17 SSTR dosimeters located on each stringer. SSTR experimental results reveal that neutron streaming, upward from the bottom of the reactor cavity region, dominates the observed neutron intensity. These absolute thermal neutron flux observations are consistent with the presence of a significant amount of fuel debris lying at the bottom of the reactor vessel. A conservative lower bound estimated from these SSTR data implies that at least 2 tonnes of fuel, which is roughly 4 fuel assemblies, is lying at the bottom of the vessel. The existence of significant neutron streaming also explains the high count rate observed with the source range monitors (SRMs) that are located in the TMI-2 reactor cavity.
\end{abstract}

KEYWORDS

Solid-State Track Recorders, Neutron Dosimetry, Three-Mile Island Unit 2 (TMI-2)

\section{INTRODUCTION}

Recent data at TMI-2 indicate that the void in the upper core region is substantial and that much of the displaced fuel appears to have been reduced to rubble. It is possible that significant amounts of this fuel debris have been relocated out of the core boundaries into off-normal locations. Location of fuel material is important in planning recovery operations for the TMI-2 facility.

TMI-2 fuel distribution assessments can be carried out nondestructively by gamma-ray and neutron dosimetry. In gamma-ray dosimetry, gamma-rays associated with specific fission products are measured. In neutron dosimetry, neutrons generated from a combination of spontaneous fission, $(\alpha, n)$ reactions, and subcritical multiplication are measured. 
Existing constraints preclude the application of many routine dosimetry methods for TMI-2 fuel distribution characterization. These constraints arise from many origins, ranging from sensitivity and background considerations to practical day-to-day restrictions of TMI-2 recovery operations. Two highly specialized methods have been applied to overcome these constraints, namely SSTR neutron dosimetry and continuous gamma-ray spectrometry with a Si(Li) Compton spectrometer. A general exposition on the applicability of SSTR neutron dosimetry for TMI-2 applications has already been published (Gold et al., 1983a). Efforts to characterize the fuel distribution in the TMI-2 makeup and the purification demineralizers with SSTR neutron dosimetry and Si(Li) gamma-ray spectrometry have been successfully completed (McNeece et al., 1983; Ruddy et al., 1983a; Ruddy et al., 1983b; Gold et a1., 1983b; Gold et al., 1984a). Preliminary results from the SSTR neutron dosimetry experiment in the TMI-2 annular gap have already been reported (Gold et al., 1984b).

\section{SSTR EXPERIMENT IN THE TMI-2 REACTOR CAVITY}

The SSTR dosimeters used in the TMI-2 annular gap consisted of 1.91-cm diameter mica track recorders and asymptotically thick $(20.0127 \mathrm{~cm})^{235} \mathrm{U}$ foil, $1.27 \mathrm{~cm} \times 1.27 \mathrm{~cm}$. Two axial stringers were deployed in the annular gap, with 17 SSTR dosimeters located on each stringer. Of the seventeen SSTR dosimeters, 14 were bare (i.e., aluminum covered) and 3 were cadmium covered. Axial locations (elevations) of these SSTR, which are shown in Figure 1, extend from the nozzles well above the core to the flow distributor plate well below the core. The region around the nozzles was of interest, since it has been speculated that some fuel debris might be lodged in the inlet or outlet nozzles.

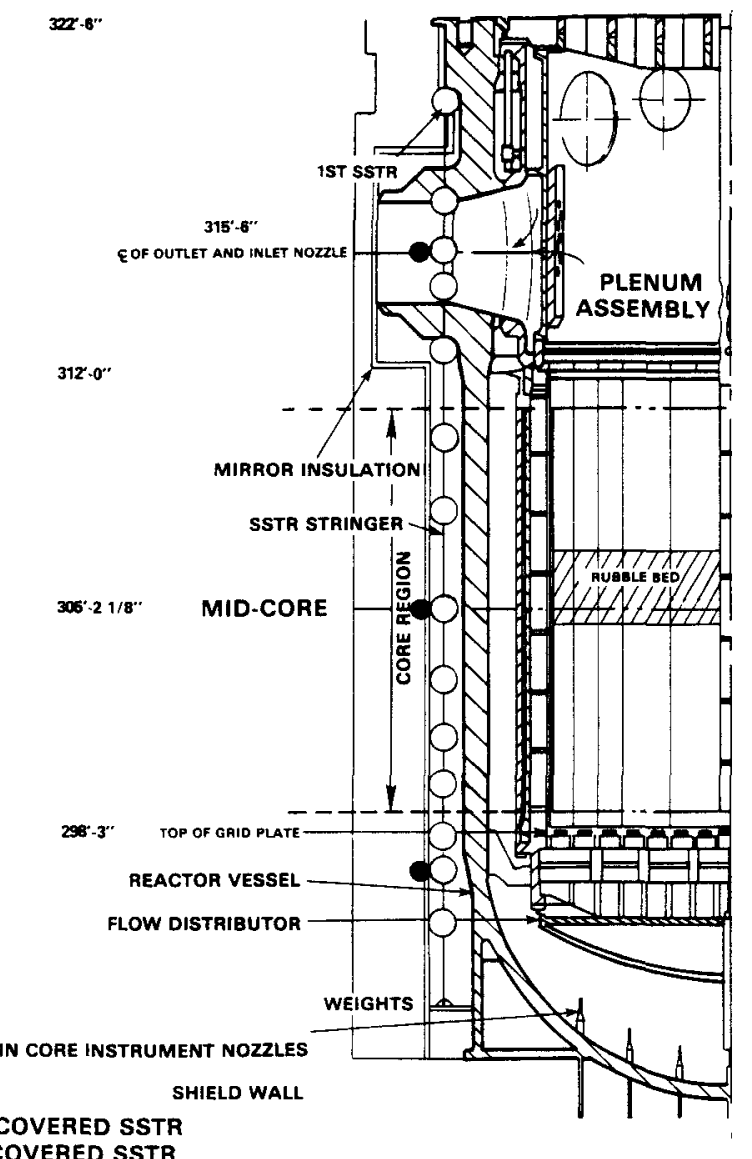

Cd COVERED SSTR
AI COVERED SSTR

HEDL S005-087.14

FIGURE 1. Deployment of SSTR Neutron Dosimeters on an Axial Stringer in the TMI-2 Annular Gap. Neg 8501182-1 
Azimuthal locations of these two stringers, the east (E-SSTR) stringer and the west (W-SSTR) stringer, were chosen near the source range monitors (SRMs). The count rate of the SRMs are roughly an order of magnitude higher than normal. The location of the SSTR stringers was chosen so that some insight into the origin of this high count rage might be provided by the SSTR dosimetry data.

These SSTR stringers were exposed in the TMI-2 annular gap for approximately three weeks, from August 19, 1983 until September 9, 1983. After retrieval, they were shipped to Hanford and processed. Preliminary appraisal of these SSTR was completed within a week and revealed track densities that were high enough to provide quantitative results. Manual scanning of these SSTRs has now been completed.

\section{ANALYSIS OF SSTR EXPERIMENTAL RESULTS}

Absolute thermal neutron fluxes obtained from these SSTR data are plotted in Figure 2 in comparison with the thermal flux anticipated for the TMI-2 reactor cavity. The curves labeled $M=2$ and $M=4$ correspond to a core multiplication of 2 and 4 , respectively. These curves were obtained by scaling of radiometric dosimetry conducted in the ANO-1 reactor cavity (Cogburn et al., 1984; Newton et al., 1984), a Babcock and Wilcox (B\&W) plant of similar design to TMI-2. Normal shutdown neutron multiplication for such a B\&W plant is $M=12$. However, the high concentration of borated water and the redistribution of the core lower the multiplication at TMI-2 down to the approximate range: $22 M<4$.

These TMI-2 annular gap results differ significantly in shape and magnitude from the thermal flux anticipated from an undisturbed core with similar borated water concentration and burnup. The TMI-2 thermal flux intensity exceeds the anticipated intensity by roughly an order of magnitude at high elevations and this difference grows with decreasing elevation to more than two orders of magnitude at the flow distributor elevation. In contrast with the axial symmetry one would expect about midplane, as is observed in the ANO-1 radiometric dosimetry data, the SSTR data for TMI-2 is clearly asymmetric.

The SSTR vertical profile of the neutron intensity is consistent with the presence of a significant amount of fuel debris lying at the bottom of the reactor vessel. Neutrons from this quantity of fuel can pass essentially unmoderated out of the reactor vessel into the concrete cavity beneath the vessel. There, they are moderated within the concrete and stream upward through the annular space between the vessel and the biological shield. A

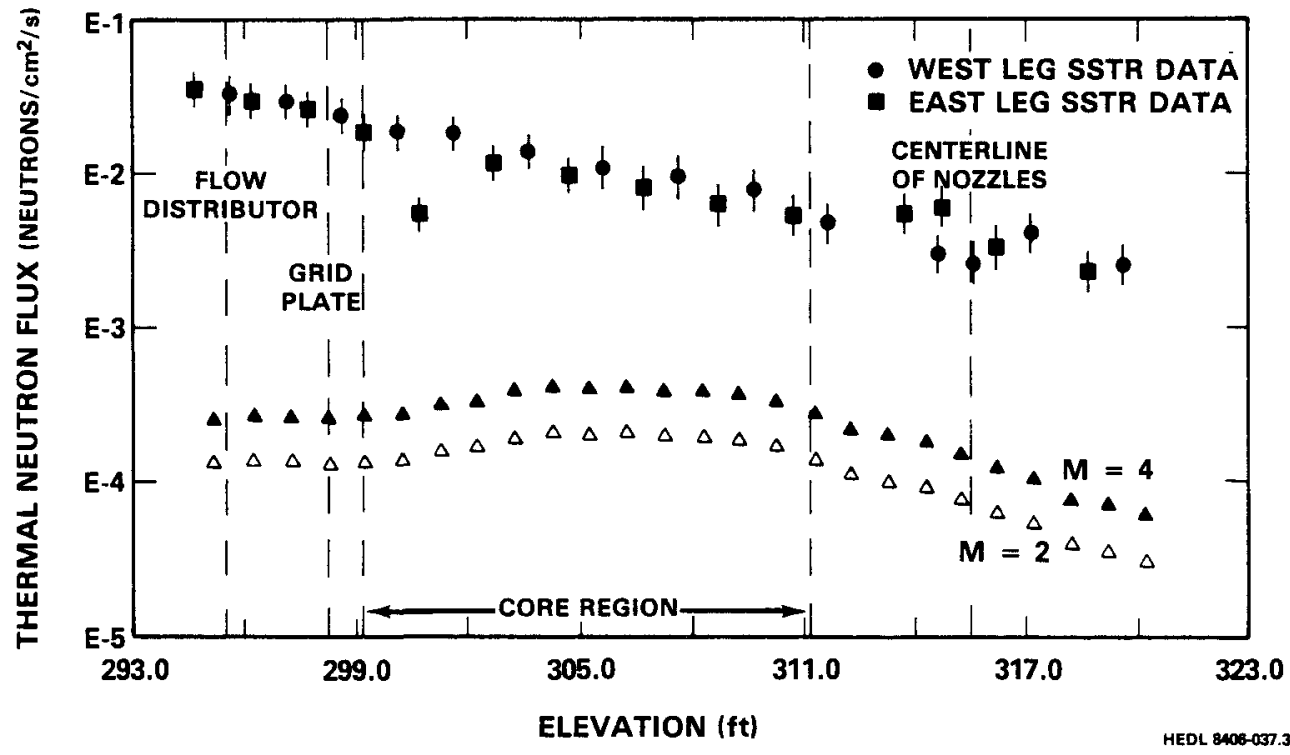

FIGURE 2. Thermal Neutron Fluxes in the TMI-2 Annular Gap. Overall experimental uncertainty is displayed at the lo leve1. Neg 8501167-1 
lower bound for the quantity of fuel lying at the bottom of the reactor vessel has been estimated from these annular gap results and calibration efforts performed for the TMI-2 demineralizer A experiment (Ruddy et al., 1983a; Ruddy et al., 1983b). This lower bound estimate is approximately 2 tonnes of fuel, which corresponds to a fuel equivalent of at least four fuel assemblies lying at the bottom of the reactor vessel.

These SSTR data show that the count rate of the SRMS, which are located near midplane in the reactor cavity, should be considerabiy higher than normal. It is recognized that the existence of significant neutron streaming must be taken into account for proper interpretation of SRM data in TMI-2 recovery operations.

\section{ACKNOWLEDGMENTS}

The support and exchange of $i$ deas with government agencies, industrial participants, and advisory groups associated with TMI-2 recovery is acknowledged; notably DOE, EPRI, NRC, GPU, RHO, and the Technical Assistance and Advisory Group (TAAG) for TMI-2 recovery. The support and guidance of WHC management is appreciated. We are grateful to $\mathrm{J}$. 0 . Henrie for discussions and review of the TMI-2 reactor system. The dedication to track scanning by P. A. Ombrellaro is also acknowledged.

\section{REFERENCES}

Cogburn C. 0., Williams J. B., and Tsoulfanidis N. (1984) Pressure vessel dosimetry at U.S. PWR plants, 5th International ASTM-EURATOM Symposium on Reactor Dosimetry, Geesthacht, Federal Repubtic of Germany, September 24-28, 1984.

Gold R., Ruddy F. H., Roberts J. H., Preston C. C., Ulseth J. A., McElroy W. N., Leitz F. J., Hayward B. R., and Schmittroth F. A. (1983a) Application of solid-state track recorder neutron dosimetry for three-mile is land unit-2 reactor recovery, Nucl. Tracks 7, 13-30.

Gold R., Roberts J. H., McNeece J. P., Kaiser B. J., Ruddy F. H., Preston C. C., Ulseth J. A. and McElroy W. N. (1983b) Fuel debris assessment for three-mile island unit-2 reactor recovery by gamma-ray and neutron dosimetry, 6th International conference on Nondestructive Evaluation in the Nuclear Industry, Zurich, Switzerland, November 27December 2, 1983.

Gold R., Roberts J. H., Ruddy F. H., Preston C. C., McNeece J. P., Kaiser B. J., and McETroy W. N. (1984a) Characterization of fuel distributions in the three-mile is land unit-2 reactor system by neutron and gamma-ray dosimetry, HEDL-SA-3063, 5 th International ASTM-EURATOM Symposium on Reactor Bosimetry, Geesthacht, Federal Republic of Germany, September 24-28, 1984.

Gold R., Roberts J. H., Ruddy F. H., Preston C. C., MCElroy W. N., Rao S. V., Greenborg J., and Fricke V. R. (1984b) Solid-state track recorder neutron dosimetry in the three mile is 1 and unit-2 reactor cavity, Trans. Am. Nucl. Soc. 47, 114.

McNeece J. P., Kaiser B. J., Gold R. and Jenkins W. W. (March 1983) Fuel Assessment of the Three-Mile Is land Unit-2 Makeup Demineralizers by Compton Recoil ConEinuous Garma-Ray Spectrometry, HEOL-7285, Hanford Engineering Development Laboratory, Richland, WA.

Newton Jr T. H., Coburn C. O., and Williams J. G. (1984) Use of stainless steel flux monitors in pressure vessel surveillance, 5 th International ASTM-EURATOM Symposium on Reactor Dosimetry, Geesthacht, Federal Republic of Germany, September 24-28, 1984.

Ruddy F. H., Roberts J. H., Gold R., Preston C. C. and Ulseth J. A. (August 1983a) Solidstate track recorder neutron dosimetry measurements for fuel debris location in the threemile island unit-2 makeup and purification demineralizer, HEDL-SA-2834, Hanford Engineering Development Laboratory, Richland, WA.

Ruddy F. H., Roberts J. H., Gold R. and Preston C. C. (1983b) Applications of solid-state track recorder neutron dosimetry for fuel debris location in the three-mile island unit-2 makeup and purification demineralizers, 12th International Conference on Solid-State Nuclear Track Detectors, Acapulco, Mexico, September 4-10, 1983. 


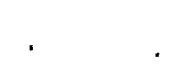

